\title{
Lymphoma of the Tonsil: A Case Report
}

\section{Tonsil Lenfoması: Olgu Sunumu}

\author{
Özlem Çelebi Erdivanlı ${ }^{1}$, Zerrin Özergin Coşkun ${ }^{1}$, Recep Bedir $^{2}$, Abdülkadir Özgür $^{1}$, Doğukan Özdemir ${ }^{1}$, \\ Suat Terzi ${ }^{1}$, Engin Dursun ${ }^{1}$ \\ ${ }^{1}$ Recep Tayyip Erdoğan Üniversitesi Tıp Fakültesi Eğitim Ve Araştırma Hastanesi, Kulak Burun Boğaz Ana \\ Bilim Dalı, Rize, Türkiye \\ ${ }^{2}$ Recep Tayyip Erdoğan Üniversitesi Tıp Fakültesi Eğitim Ve Araştırma Hastanesi, Patoloji Ana Bilim Dalı, \\ Rize, Türkiye
}

\section{ÖZET}

Edinilmiş bağışıklık eksikliği sendromunun (AIDS) ortaya çıkması ve AIDS ile ilişkili lenfomaların görülmeye başlanması Burkitt lenfoma (BL) insidansının artmasına neden olmuştur. Bu çalışmada, tonsilde nekrotik ve ülsere hipertrofisi olan, insan bağışıklık yetmezlik virüsü (HIV) pozitifliği mevcut ve tonsillektomi sonrası patoloji sonucu Burkitt lenfoma ile uyumlu olan bir hasta literatür eşliğinde değerlendirilerek sunuldu. Yaklaşık 2 haftadır boğaz ağrısı, ateş, yutma güçlüğü şikayetleri olan 54 yaşında erkek hasta bu şikayetlerinin ilaç tedavisi ile gerilememesi sonucu kliniğimize başvurdu. Hastanın sol tonsilinin hipetrofik, üzerinin nekrotik ülsere görünümde olduğu dikkat çekti. Hastanın laboratuvar tetkiklerinde HIV pozitifliği saptandı. Hastaya genel anestezi altında tonsillektomi uygulandı, patoloji sonucu Burkitt lenfoma olarak geldi. Hasta tedavi amaçlı onkoloji bölümüne yönlendirilerek kemoterapisi başlandı. Özellikle erişkin hastalarda, belirlenmiş klinik risk faktörlerinin bulunduğu durumlarda tonsillektomi materyallerinin daha dikkatli ve malignite göz önüne alınarak yapılması gerektiğini düşünmekteyiz.

Anahtar Kelimeler: Tonsil; Burkitt lenfoma; HIV

\begin{abstract}
The emergence of AIDS and AIDS related lymphomas have led to increased incidence of Burkitt lymphoma. In this study, the patient who has diagnosed as HIV and Burkitt lymphoma after tonsillectomy was presented. Fiftyfour years old male patient who complained of sore throat, fever and odynophagia about 2 weeks has admitted to our clinic. The view of the left tonsil was hypertrophic, necrotic and ulcerative. The patient was found to be HIV positive. Tonsillectomy was performed under general anesthesia. Pathologic examination revealed Burkitt lymphoma. With this pathology result, the patient was referred to the department of medical oncology for chemotherapy. We believe that, tonsillectomy specimens should be examined more carefully especially in patients with clinical risk factors.
\end{abstract}

Key words: Tonsil; Lymphoma; HIV

\section{Giriş}

Baş-boyun bölgesi lenfomaları, yassı hücreli karsinomların ardından en sık görülen başboyun neoplazilerdir ve bu bölgedeki malignitelerin \%2-3'ünü olușturmaktadır (1). Bu bölgede Waldeyer halkasinın en sik tutulan lokalizasyon olduğu bildirilmekle birlikte, bu lenfoid kompartmanda en belirgin tutulum yeri tonsildir (2). Tonsiller bölgede en sik görülen lenfomalar B hücreli non-Hodgkin lenfomalardir (NHL) (1).

Burkitt lenfoma (BL), en s1k görülen çocukluk yaşı NHL'sidir. BL sekizinci kromozomdaki c-myc geninin translokasyonu ile karakterizedir. Afrika tipinin (Endemik tip)
Epstein-Barr virüsü ile iliskisi bilinmektedir. Yüz kemikleri ve çeneyi tutar. Sporadik tipi genellikle gastrointestinal sistem, overler, böbrekleri tutar. İnsan bağışıklık yetmezlik virüsü (HIV) ile enfekte olan kişilerde de hastalığın bir başka tipi gelişebilir (3).

$\mathrm{Bu}$ çalışmada, tonsilde nekrotik ve ülsere hipertrofisi olan, HIV pozitifliği mevcut ve tonsillektomi sonrasi patoloji sonucu BL ile uyumlu olan bir hasta literatür eşliğinde değerlendirilerek sunuldu.

\section{Olgu Sunumu}

Yaklaşık 2 haftadır boğaz ağrısı, ateş, yutma güçlüğü şikayetleri olan 54 yaşında erkek hasta 
bu şikayetlerinin ilaç tedavisi ile gerilememesi sonucu kliniğimize başvurdu. Hastanın orofarengeal muayenesinde sol tonsilinin oldukça hipertrofik, tonsil yüzeyinin ülsere ve nekrotik görünümde olduğu izlendi (Resim 1).

Boyunda palpabl kitlesi ve trismusu olmayan hastanın odinofajisi mevcuttu. Periferik lenf nodu, ateş ve hepatosplenomegalisi olmayan hastanın diğer muayenelerinde patolojiye rastlanmadi. Bilgisayarl1 tomografide (BT), orafarenks ve hipofarenks düzeyinden geçen kesitlerde sol parafarengeal yerleşimli yaklaşık $41 \times 31 \mathrm{~mm}$ ebatlarında lobüle konturlu yumuşak doku dansitesinde hafif heterojen dansitede kitle lezyonu izlendi. Lezyon lokalizasyonunda parafarengeal yağ planları silinmiş olarak izlendi. Görünüm malign karakterde kitle lezyonu ile uyumlu bulundu (Resim 2A). Magnetik rezonans (MR) görüntülemesinde ek olarak sol palatin tonsilin hipertrofik olduğu, konturlarında lobülasyon dikkati çekti. Kitlenin orofarenks hava sütununu sol lateralden belirgin daralttığ izlendi (Resim 2B). Hastanın hemogram ve biyokimyasal değerlendirmesinde, WBC $3.9 \mathrm{~K} / \mathrm{uL}$, HB: 10.6 g/dL, HTC: $33.0 \%$, PLT: $120000 \mathrm{KuL}, \mathrm{CRP}$ : $0.69 \mathrm{mg} / \mathrm{dL}$, Sedimentasyon: $24 \mathrm{~mm} / 1$ saat, AST: $38 \mathrm{U} / \mathrm{L}$, ALT: $24 \mathrm{U} / \mathrm{L}$, Üre: $30 \mathrm{mg} / \mathrm{dL}$, Kreatin: $1.03 \mathrm{mg} / \mathrm{dL}$ olarak saptandı. Hastanın Elisa tetkiklerinde ise HIV pozitifliği saptandi. Ankara Refik Saydam Hifzıssıhha Merkezi'ne yollanan kan örneklerinde HIV RNA pozitifliği doğrulandı. Bu sırada hastaya genel anestezi altında tonsillektomi uygulandi. Patolojik incelemede B hücreli NHL infiltrasyonu (high grade) saptand1 (Resim 3). Histopatolojik ve immünhistokimyasal bulguların BL ile uyumlu olduğu belirtildi. İmmünohistokimyasal incelemede neoplastik hücrelerde CD20 (+), CD10 (+), CD3 (-), bcl 2 $(-)$, CD138 (-) ve Kİ67 proliferasyon indeksi $\% 100$ pozitif sonuç verdi (Resim 4,5). Hasta kemoterapi amaci ile onkoloji kliniğine, antiretroviral tedavi amaciyla enfeksiyon kliniğine yönlendirildi
Çalışmalarda tonsil lojunda en sık görülen lenfoma tipinin B hücreli NHL olduğu ve ekstranodal yerleşim olarak \%60-70 oranında Waldeyer halkası tutulumu bildirilmiştir (4-6). Tonsil tutulumu gösteren NHL'lerde ortalama yaş 59 olarak bildirilmiştir (4). Olgumuzda da, literatürle uyumlu olacak şekilde hasta yaş 54 idi. Başlıca klinik bulgular boğaz ağrısı, tonsil büyümesi, yutma güçlüğü, boyunda kitle varlığ 1 ve işitsel yakınmalardır (7). Tonsiller lenfomaların yaklaşık \%10'u sistemik yakınmalara sahip hastalardır. Genellikle MR ile tonsil yerleşi-mindeki kitle saptanır.

Tek taraflı asimetrik tonsil büyümesinde malignite şüphesi nedeniyle tonsillektomi planlanır. Primer tonsil maligniteleri tüm insan malignitelerinin \%2'sini oluşturur. En s1k görülen tonsil tümörü yass1 hücreli karsinomdur (\%75). En s1k görülme şekli tonsilde tek taraflı büyüme ve mukozada ülserasyondur. İkinci sık görülen tonsil tümörü lenfomalardır $(1,8)$. Daha çok submukozal kitle şeklinde karşımıza çıksa da asimetrik hipertrofi de yapmaktadırlar $(8,9)$. Malignitenin dișında, benign tümörler, tekrarlayan enfeksiyonlar, lipid depo hastalıkları, tüberküloz ve aktinomikoz gibi kronik enfeksiyonlar ve komşu yapıların patolojilerinin de tonsilde tek taraflı asimetrik büyümeye neden olabileceği literatürde bildirilmektedir (8).

Beaty ve ark. erişkin hastalarda tonsillektomi materyallerinin histopatolojik incelemeye alınması için, kanser öyküsü olması, tonsilde asimetrik büyüme, tonsilde palpabl kitle, tonsil üzerinde şüpheli lezyon, boyunda kitle, açıklanamayan kilo kaybı ve halsizlik, gece terlemeleri, ateș ve iștahsızlık gibi kriterler bildirmișlerdir (10). Alvi ve Vartainan, 288 tonsillektomi materyali içinde sadece 1 hastada lenfoma tanis1 (peritonsiller apse tanıs1 ile tonsillektomi olan 65 yaşında erkek hasta) olduğunu bildirmişlerdir (11). Younis ve ark. 2438 adenotonsillektomi kaydını inceledikleri (2099 çocuk, 339 erişkin) çalışmalarında çocukluk çağında hiçbir maligniteye rastlamamıșlarken erișkin grubunda 40 hastada malignite bulmuşlar. Dolayısıyla özellikle erişkin grubunda gross patolojik incelemenin yeterli olduğunu, ancak

\section{Tartışma}




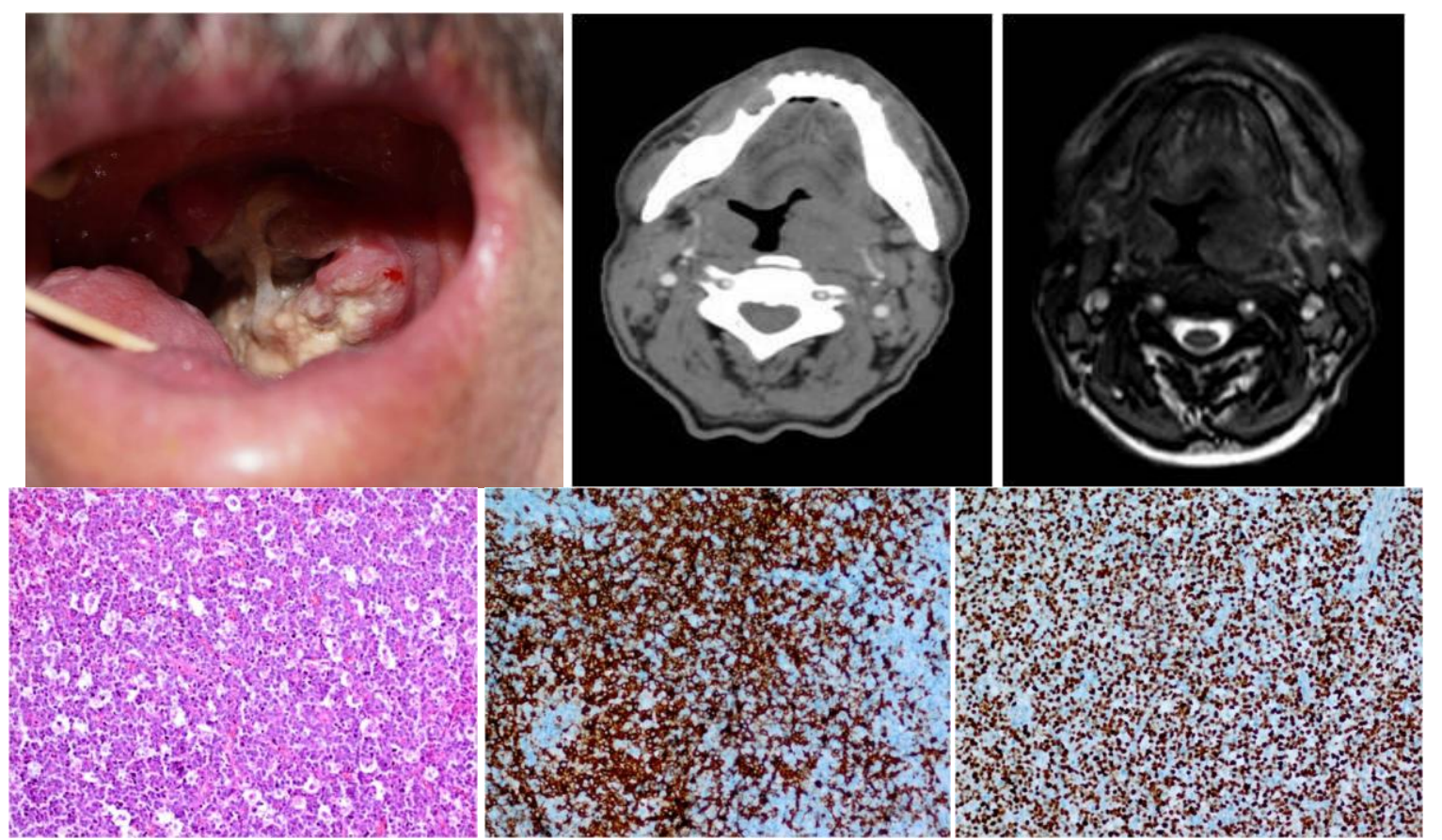

Resim 1: Hipertrofik tonsil yüzeyinin ülsere ve nekrotik görünümü, 2: Kitlenin tomografi görüntüsü, 3: Kitlenin magnetik rezonans görüntüsü, 4: Diffüz infiltrasyon gösteren tingible-body makrofajlar (yıldızlı gökyüzü manzaras1) içeren atipik lenfoid hücre infiltrasyonu (H\&E, x200), 5: Neoplastik hücrelerde CD20 ile diffüz pozitif boyanma (x200), 6: Ki-67 ile \%100 yakın diffüz pozitif boyanma (x200)

risk faktörlerinin bulunduğu şüpheli olgularda histopatolojik inceleme yapılmasının gerekli olduğunu ileri sürmüşlerdir (12).

Reiter ve ark. tek taraflı asimetrik büyüme olan 31 tonsillektomi materyalinin 2 'sinde (\%6.5) maligniteye rastlamışlardır. Her iki hasta da diffüz büyük $\mathrm{B}$ hücreli lenfoma tanısını almıştır (6).

Primer tutulum bölgesine bağlı olarak ekstranodal NHL'ler değişken bir klinik süreç ve prognoza sahiptir. Erken evre tonsiller yerleşim, diğer ekstranodal tutulumlara oranla daha iyi bir prognostik özelliğe sahiptir (13). Ancak AIDS'in ortaya çıkması ve AIDS ile ilskili lenfomalarin görülmeye baslanmasi günümüzde $\mathrm{BL}$ insidansinin artmasina neden olmustur. AIDS hastalarında görülen tüm lenfomaların \%20-40'ının BL olduğu belirlenmiştir. Tedavide aggresif çoklu ajan içeren kemoterapi protokolleri uygulanır. BL da tedaviye tam yanıt oranı \%70-90 olmakla birlikte riski yüksek hastalarda santral sinir sistemi tutulumu sıklığı ve relapslar gözönünde bulundurularak tedavi planlanmalıdır $(4,14)$. HIV pozitif hastalarda ise tedaviye yanıt ve relaps oranları benzer olmakla birlikte enfeksiyöz komplikasyonlar ve komorbid hastalığa bağlı olarak sağkalım oranlarının daha düşük olduğu tespit edilmiştir (15). Ancak etkin antiviral ajanlarm tedaviye girmesiyle birlikte hastaların \%50'sinden fazlasında uzun süreli hastalıksız sağkalım sağlanmıştır. Merkezi sinir sistemi tutulumu olan hastalarda ise tedavi yanıtları ve prognoz oldukça kötüdür (15).

Sonuç olarak, özellikle erişkin hastalarda, belirlenmiș klinik risk faktörlerinin bulunduğu durumlarda tonsillektomi materyallerinin histopatolojik incelemesinin gerekli olduğu görüşündeyiz. Peritonsiller apse ile gelen olgularda ayırıcı tanıda malign patolojiler düşünülmeli ve tedavi takibinde tonsilde şüpheli görünümde tonsillektomi ile kesin tanıya gidilmelidir.

Çıkar Çatışması: Yok

\section{Kaynaklar}

1. Kaygusuz G, Cansız C, Kuzu I, Dizbay Sak S. Tonsil maligniteleri arasında lenfoproliferatif hastalıkların dağılımı. Türk Patoloji Dergisi 2008;24:166-7

2. Epstein JB, Epstein JD, Le ND, Gorsky M. Characteristics of oral and paraoral malignant lymphoma: A population- based review of 361 cases. Oral Surg Oral Med Oral Pathol Oral Radiol Endod 2001;92:519-25 
3. Yamaç D. Baş ve boyun bölgesi hodgkin ve nonhodgkin lenfomaları. KBB ve BBC Dergisi 2003;11 :125-40

4. Barton JH, Osborne BM, Butler JJ, et al. NonHodgkin's lymphoma of the tonsil. A clinicopathologic study of 65 cases. Cancer 1984;53:86-95

5. Kaur P, Nazeer T. B-cell chronic lymphocytic leukemia/small lymphocytic lymphoma presenting in the tonsil: a case report and review of literature. Am J Otolaryngol 2004;25:121-5

6. Reiter ER, Randolph GW, Pilch BZ. Microscopic detection of occult malignancy in the adult tonsil. Otolaryngol Head Neck Surg 1999;120:190-4

7. Saul SH, Kapadia SB. Primary lymphoma of Waldeyer's ring. Clinicopathologic study of 68 cases. Cancer 1985;56:157-66

8. Doğan R, Tuğrul S, Eren SB. Peritonsiller apse ile gelen diffüz büyük $\mathrm{B}$ hücreli lenfoma. Türk Otolarengoloji Arșivi 2012;50:50-3

9. Cinar F. Significance of asymptomatic tonsil asymmetry. Otolaryngol Head Neck Surg 2004;131:101-3
10. Beaty MM, Funk GF, Karnell LH, et al. Risk factors for malignancy in adult tonsils. Head Neck 1998;20:399-403

11. Alvi A, Vartanian AJ. Microscopic examination of routine tonsillectomy specimens: it is necessary? Otolaryngol Head Neck Surg 1998;119:361-3

12. Younis RT, Hesse SV, Anand VK. Evaluation of the utilityand costeffectiveness of obtaining histopathologic diagnosis on all routine tonsillectomy specimens. Laryngoscope 2001;111:2166-9

13. Economopoulos T, Fountzilas G, Kostourou A, et al. Primary extranodal non-Hodgkin's lymphoma of the head and neck in adults: a clinicopathological comparison between tonsillar and nontonsillar lymphomas. Anticancer Res 1998;18:4655-60

14. Ekici K, Erdem ME, Şahin G, ve ark. Midenin Burkitt lenfoma olgusu ve literatürün gözden geçirilmesi..J Kartal TR 2014.34392

15. Kaplan LD. HIV-associated lymphoma. Best Practice and Research Clinical Haematology 2012;25:101-7 